\title{
ANALYSIS OF THE IMPACT OF DROPLETS ONTO WATER FILMS IN DRIFT ELIMINATORS
}

\author{
J. LÓPEZ ${ }^{1}$, A. S. KÁISER ${ }^{1}$, B. ZAMORA ${ }^{1}$, A. VIEDMA ${ }^{1}$, J. A. VERA ${ }^{1}$, \\ M. JIMÉNEZ ${ }^{2}$ J. RUIZ ${ }^{2} \&$ M. LUCAS ${ }^{2}$ \\ ${ }^{1}$ Department of Thermal and Fluids Engineering, Polytechnic University of Cartagena, Spain. \\ ${ }^{2}$ Department of Energy and Mechanical Engineering, Miguel Hernández University of Elche, Spain.
}

\begin{abstract}
Water droplets emitted from cooling towers must be prevented for several reasons, human health hazards are the most important ones. The generation and control of these droplets are the main tasks for drift eliminators: devices installed inside mechanical draft cooling towers useful to prevent water droplets, originated by the crossflow between air and water inside the tower, from being released into the environment. This is the phenomenon called 'drift'. In this paper, the operating conditions of a type of drift eliminator placed in a cooling tower are studied. This work is focused on the numerical and experimental characterization of the multiphase flow taking place when water droplets, drifted by the airstream, impact on the water film formed over the drift eliminators plates. The problem of these drop impacts has been studied throughout an experimental installation and a numerical model has been developed throughout the ANSYS software and several VOF multiphase flow simulations have been carried out showing a good agreement with experimental data.
\end{abstract}

Keywords: CFD, cooling tower, drift eliminator, drop impact, water film.

\section{INTRODUCTION}

Mechanical draft cooling towers are components for heat dissipation in air-conditioning systems. Its operating principle is based on the adiabatic evaporation of a small part of the circulating water, cooling the rest. The water enters the cooling tower by spray, or by free fall, into a crossflow airstream. The adiabatic evaporation of a small part of the water induced by the contact with the air results in the cooling of the rest of the water collected in a lower tank described by Lucas et al. [1].

The efficiency of cooling towers is higher than any other alternative cooling system. However, the use of these devices is limited because they can release into the environment drops of water (a phenomenon called drift), which may contain harmful chemicals or microorganisms. Drift eliminators are installed inside the tower to reduce the release of water drops into the environment through the impact of these drops on drift eliminator's plates [2].

Drift eliminators are made up of several plates placed inside the cooling tower forming angles, so that water droplets can collide with them and do not follow the airstream outside. The changes in direction caused by the plates generate pressure losses that can lead to the reduction of the heat exchange within the tower, or the increase in the air vent's power needed. In any case, they result in a reduction of the global cooling system efficiency. The rate of drift loss is a function of tower configuration, eliminator design, airflow rate through the tower and water loading.

An experimental investigation of drop impacts onto dry walls and liquid films is done by Sikalo et al. [3] quantifying the critical impact angle at which rebounding first occurs in terms of

This paper is part of the Proceedings of the $8^{\text {th }}$ International Conference on Computational and Experimental Methods in Multiphase and Complex Flow (Multiphase Flow 2015)

www.witconferences.com
} 
the normal Weber number. Moreover, Nikolopoulos et al. [4] numerically studied the normal impingement of a drop onto a wall film using the VOF model; they determined the conditions for the crown formation and breakup and also the bounds between droplet deposition and splashing. Lunkad et al. [5] carried out numerical simulations to characterize the drop impact and spreading onto dry horizontal and inclined surfaces; several aspects of this computational domain and boundary conditions are considered to improve the numerical model used in the present paper, such as the size of the domain or the no slip boundary condition specified at the wall.

In short, the challenge in this research is to set the proper operating conditions for the cooling tower so that the droplet emission to the ambient could be avoided; there are different sources of droplet developing on the geometry of the drift eliminator. One of them is the droplets rebounded from the wet plates of the drift eliminator. Therefore, this paper is focused on drop impact onto the water film formed over the plate; these falling drops can generate smaller drops as a consequence of the impact, and these new drops are more easily drifted by the crossflow airstream.

To study these phenomena, an experimental study and a numerical simulation of the impact of droplets onto water film in an L-shaped drift eliminator is carried out. A description of the experimental installation and procedure, the numerical modelling and the main results obtained are presented below.

\section{EXPERIMENTAL APPARATUS AND PROCEDURE}

\subsection{Description of the experimental prototype}

An experimental prototype of mechanical draft cooling tower has been set up to do the tests needed to get the described objectives. The prototype consists of a prismatic structure formed by a metallic frame and four transparent walls (Fig. 1).

The test section, at the central part of the tower, is removable to allow easier changes (Fig. 2); it contains the drift eliminator and it is the region where main measurements are taken.

The air supply system consists of one centrifugal vent $(0.55 \mathrm{~kW})$ placed next to the bottom of the tower, and a regulator; it is shown in Fig. 1.

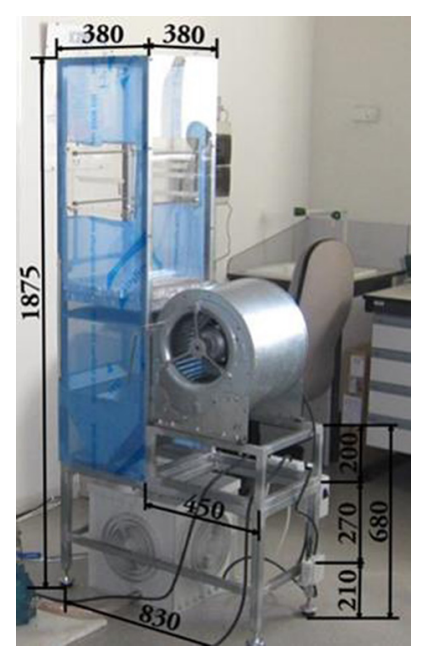

Figure 1: Experimental cooling tower. 


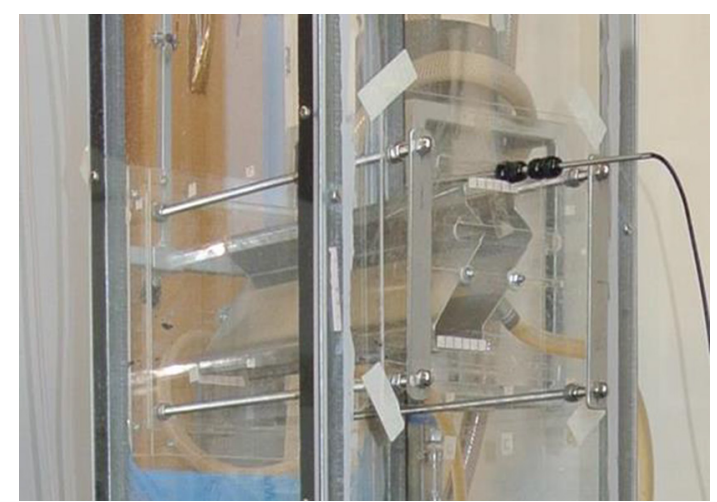

Figure 2: Test section and the hot wire anemometer.

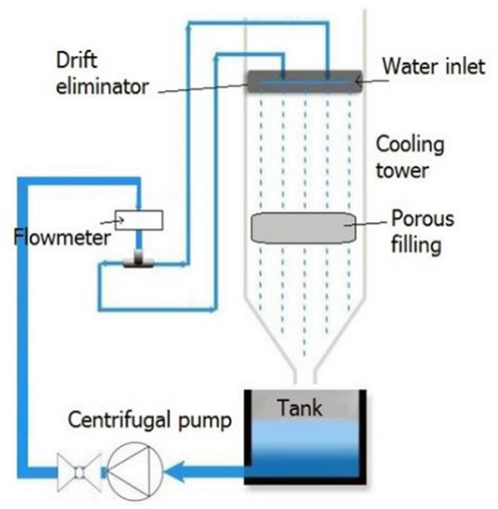

Figure 3: Water supply system.

The water supply system (Fig. 3) is designed to maintain a constant value for water mass flow at the inlet placed on one of the plates of the drift eliminator. This system consists of a centrifugal pump taking water from the lower tank and pumping it to the test section. The water goes through a flowmeter before it is introduced through a slot on the plate. Once the water is on the plate, it forms a film that, in the absence of a strong enough air flow, runs down falling to the porous filling and farther down to the lower tank, finally returning to the circuit.

Additionally, a droplet generator (model TSI MDG100) is installed above the test section to analyse the impact of droplets. Droplet size and velocity is set in this generator.

Water is usually sprayed below the drift eliminator and above the porous filling; however, our study is focused on the droplets generated in the drift eliminator, so the water film will be considered to be formed directly over the plate. This water film is originated in actual cooling towers when droplets from the spray gather on the plate. Then, the water film is swept away by the airstream, as explained by Arienti et al. [6] and goes up or down due to the airstream force or gravity, respectively. This paper tries to characterize the impact of water droplets on this film as a function of the size and velocity of the droplet. 


\subsection{Data acquisition system and uncertainty calculation}

The variables needed when carrying out the experimental tests are the water flow rate injected in the tower and the air velocity. A hot wire anemometer (model TSI 8465) is used to measure the air velocity in the test section, at three different heights in the channel zone formed by the two plates. A Pitot tube (model SR 305) and a differential pressure transducer (model DPT100-R2Az-D-Span) are preferred to measure the air velocity when the water is circulating. Additionally, an electromagnetic flowmeter is used to measure the water flow entering the tower. All these measures are registered through a data acquisition system with a resolution of 16 bits and a maximum of eight analogical inputs.

The images and videos needed to measure the size of droplets and the effect of the impacts on the water film were taken by a high-velocity camera (model MIKROTRON Eosens 3CL).

To calculate the uncertainty of the measurement process, the advices of the reference guide ISO [7] have been followed. Total uncertainty is $0.0658 \mathrm{~m} / \mathrm{s}$ for Pitot tube; $0.095,0.138$ or $0.196 \mathrm{~m} / \mathrm{s}$ (depending on the selected range) for hot wire anemometer and $0.003,0.019$ or $0.036 \mathrm{~L} / \mathrm{min}$ (depending on the range) for the flowmeter.

\subsection{Experimental test plan}

To characterise this phenomenon, some parameters are needed such as K parameter or Reynolds and Ohnesorge numbers. Parameter K is the wave number of the droplet, this relates the size of the drop and its velocity; and the Ohnesorge number relates the viscous forces to inertial and surface tension forces. Several variables have to be measured so that these parameters can be calculated: water flow rate is set for each experimental test in $0.22 \mathrm{~L} / \mathrm{min}$; water film thickness depends on the flow rate, and it is also constant in each test and its mean value is $0.5 \mathrm{~mm}$, measured through image processing; droplet velocity and diameter are also measured by image processing, and both variables depend on the droplet generator settings.

For each experimental test, droplet velocity and diameter are measured and used to calculate the needed parameters.

\section{NUMERICAL MODELLING}

\subsection{Computational domain}

To simulate the impact of droplets onto the water film occurring inside the tower, a small 3D domain is employed. This domain consists of the part of the plate where the drop is falling (Fig. 4).

This domain has been meshed with hexahedrons of $200 \mathrm{~mm}$ as maximum; this size is large enough to simulate the air flow; however, in water zones a dynamic adaptive mesh refinement is used to improve the precision of the solution. Mesh elements become four times smaller when applying the dynamic refinement, and it is applied when the element has a water volume fraction of 0.3 or higher. The 0.3 value is set due to the water-air interface criterion, usually set in 0.5 as Lan et al. [8] determined.

\subsection{Boundary conditions}

Regarding on boundary conditions, the symmetry condition is set in both lateral faces of the domain; wall conditions is set in the lower face of the domain, representing the plate of the 


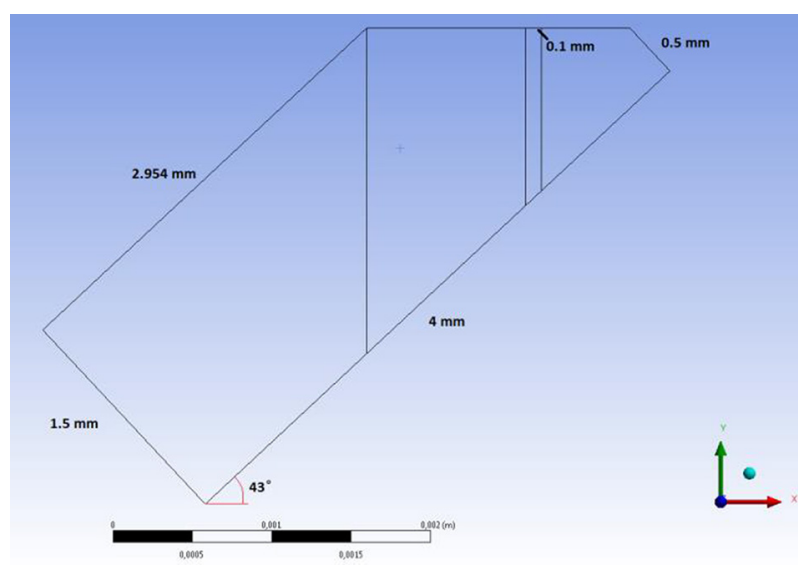

Figure 4: Computational domain.

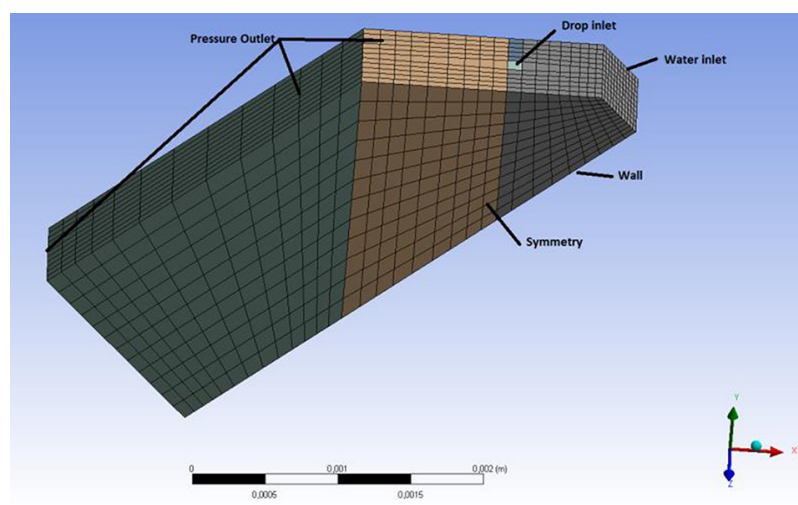

Figure 5: Mesh and boundary condition details.

drift eliminator, with a contact angle between air, water and the plate of $30^{\circ}$; a velocity inlet boundary condition is employed to define the water entrance representing the water film formed over the separator plate with a value for film thickness of $0.5 \mathrm{~mm}$. Also, a velocity inlet boundary condition is employed to define the droplets entrance; in this case, a UDF is used to create the droplets.

Moreover, pressure outlet boundary conditions are set to define the rest of faces, setting the value for gauge pressure in each one from computational data obtained in a previous study. Figure 5 shows the domain with the boundary conditions.

\subsection{Numerical approach}

In this numerical study, a laminar regime is supposed considering the fact that no airstream is injected in the domain. The multiphase volume of fluid (VOF) model is employed to calculate the solution of the drop impact. The VOF model can reproduce two or more immiscible fluids by solving a single set of momentum equations and tracking the volume fraction of 
each of the fluids throughout the domain. With regard to numerical convergence, for each time step, the criterion is a value for the continuity residual of $10^{-4}$.

Regarding on air and water interaction, wall adhesion option is enabled and a value of $0.073 \mathrm{~N} / \mathrm{m}$ is set for surface tension, taking into account a previous study from our department. Moreover, the contact angle between air, water and the plate is set at $30^{\circ}$ and the wall roughness is also considered.

The VOF method needs a specific solution method, such as geo-reconstruct, CICSAM, compressive, QUICK or modified HRIC. The modified HRIC (high-resolution interface capturing) solution method is used in these simulations. This scheme is a composite NVD scheme that consists of a non-linear blend of upwind and downwind differencing [9].

Attending to the Courant number, which is one of the most relevant variables in these simulations, it is set at 0.25 once the convergence of the problem is proved. The Courant number relates the size of cells forming the interface between air and water and the time step size. In these simulations, the global Courant number remains constant while the time step size varies; this way no problems on simulation convergence appear. Initial time step size is $10^{-6} \mathrm{~s}$, and it is calculated throughout the Courant number and the mean size of cells.

\section{RESULTS AND DISCUSSION}

Results for drop impact simulations are presented in this point, and also the experimental tests carried out to validate the computational model. Moreover, the impact of droplets is characterized for each test, and operating conditions for the cooling tower are set to prevent the generation of water droplets because of these impacts.

\subsection{Droplet impact experimental results}

Several cases are studied, characterizing the behaviour of the droplets as a function of the water flow rate injected by the droplet generator. To study this aspect of the problem, some images and videos are taken and analysed computationally, obtaining values for droplet velocity and size for each case (Fig. 6).

In Table 1, Q is defined as the water flow injected by the droplet generator, it is set throughout the injection system; $\mathrm{f}$ is the vent regulator frequency, set from the regulator installed in the software LabView; $d_{0}$ is referred to the mean droplet diameter and it is measured when digitally analysing the images taken from tests; $\mathrm{w}_{0}$ is the mean droplet velocity, also measured by digital analysis; D means the nozzle diameter used in the test; $\mathrm{Q}^{*}$ is the water flow injected over the plate to form the water film, it is also set by LabView controller; and finally Reynolds, Ohnesorge and K numbers are calculated.

Table 1 shows different calculated variables.
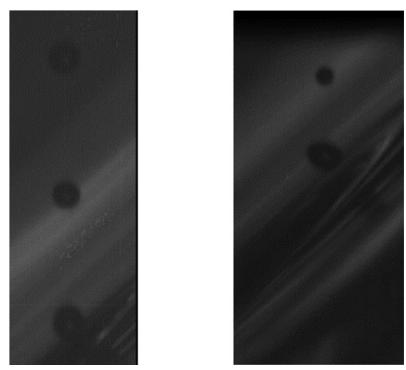

Figure 6: Experimental images of droplet impact. 
Table 1: Calculated variables.

\begin{tabular}{lcccccccc}
\hline Test & $\mathrm{Q}(\mathrm{ml} / \mathrm{h})$ & $\mathrm{d}_{0}(\mu \mathrm{m})$ & $\mathrm{w}_{0}(\mathrm{~m} / \mathrm{s})$ & $\mathrm{D}(\mu \mathrm{m})$ & $\mathrm{Q}^{*}(\mathrm{~L} / \mathrm{min})$ & $\mathrm{Re}$ & $\mathrm{Oh}$ & $\mathrm{K}$ \\
\hline 1 & 133 & 152.02 & 4.7 & 100 & 0.22 & 713.07 & 0.03 & 111.60 \\
2 & 110 & 142.69 & 3.89 & 100 & 0.22 & 553.95 & 0.03 & 106.43 \\
3 & 100 & 138.23 & 3.54 & 100 & 0.22 & 488.36 & 0.03 & 103.92 \\
4 & 90 & 133.46 & 3.18 & 100 & 0.22 & 423.55 & 0.03 & 101.22 \\
5 & 80 & 128.32 & 2.83 & 100 & 0.22 & 362.42 & 0.03 & 98.28 \\
6 & 70 & 122.94 & 2.48 & 100 & 0.22 & 304.28 & 0.03 & 95.18 \\
7 & 60 & 116.78 & 2.12 & 100 & 0.22 & 247.08 & 0.03 & 91.58 \\
8 & 50 & 109.72 & 1.77 & 100 & 0.22 & 193.82 & 0.04 & 87.39 \\
9 & 40 & 101.85 & 1.41 & 100 & 0.22 & 143.32 & 0.04 & 82.65 \\
10 & 63 & 118.70 & 2.23 & 100 & 0.22 & 264.17 & 0.03 & 92.70 \\
11 & 64 & 119.32 & 2.26 & 100 & 0.22 & 269.12 & 0.03 & 93.07 \\
12 & 65 & 119.94 & 2.3 & 100 & 0.22 & 275.31 & 0.03 & 93.43 \\
13 & 75 & 125.80 & 2.65 & 100 & 0.22 & 332.70 & 0.03 & 96.83 \\
14 & 55 & 180.08 & 1.95 & 100 & 0.22 & 350.45 & 0.03 & 126.72 \\
15 & 50 & 174.45 & 1.77 & 100 & 0.22 & 308.16 & 0.03 & 123.74 \\
16 & 45 & 168.43 & 1.59 & 100 & 0.22 & 267.27 & 0.03 & 120.52 \\
17 & 45 & 106.11 & 1.59 & 100 & 0.22 & 168.38 & 0.04 & 85.22 \\
18 & 90 & 133.68 & 3.12 & 100 & 0.00 & 416.26 & 0.03 & 101.35 \\
19 & 133 & 152.27 & 4.52 & 100 & 0.00 & 686.89 & 0.03 & 111.74 \\
\hline
\end{tabular}

It can be observed that as the droplet velocity increases, its size is larger, an effect introduced by the droplet generator when the water flow rate vary. In previous tables, some experimental tests are described, it is observed that droplet rebound appears when the Reynolds number of the water droplet decreases. Tests at Re number higher than 360 show droplets joining the film and not rebounding over it in most cases. This phenomenon can be explained considering the kinetic energy of the droplet: as this energy increases, the possibility of breaking the film surface increases too, so the droplet can join the film. However, droplets with lower kinetic energy cannot break the film surface and rebound.

\subsection{Computational results}

Several simulations were carried out to describe the behaviour of water droplets impacting onto the water film. A comparison between experimental and numerical results is done. For example, experimental test 1 is simulated computationally, and it is carried out by setting the boundary conditions.

In Fig. 7, a groove formed after the drop impact is observed. Also, in experimental test 1 that groove is observed as can be seen in Table 2 . The computational model developed for this study gets a good agreement with the experimental tests regarding the similarities of the drop impact behaviour. 
Table 2: Test comments.

\begin{tabular}{ll}
\hline Test & Comments \\
\hline 1 & Water droplet joins the film forming a groove \\
2 & Water droplet joins the film forming a groove \\
3 & Water droplet joins the film forming a groove \\
4 & Water droplet joins the film forming a groove \\
5 & Water droplet joins the film without groove \\
6 & Rebound limit \\
7 & Droplet size decreases after rebound \\
8 & Droplet size decreases after rebound \\
9 & Unsteady test \\
10 & Low rebound \\
11 & Low rebound \\
12 & Low rebound \\
13 & Water droplet joins the film without groove \\
14 & Significant rebound \\
15 & Significant rebound \\
16 & Significant rebound \\
17 & Significant rebound \\
18 & Dry plate, no splash \\
19 & Dry plate, no splash \\
\hline &
\end{tabular}

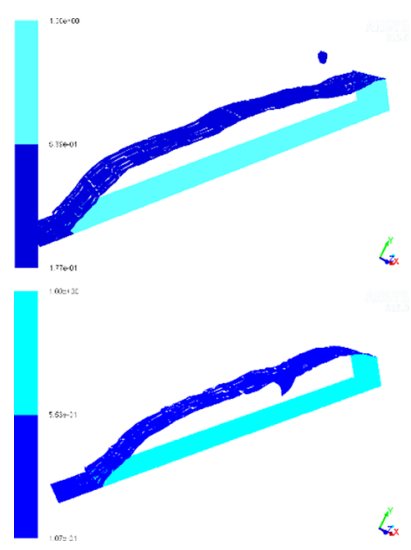

Figure 7: Droplet impact sequence. Water drop is seen in the first figure, and the groove formed after the impact in the second one. 


\section{CONCLUSIONS}

As the main objective of this paper, the characterization of the impact of droplets onto the water films formed over drift eliminator plates inside cooling towers is carried out in this paper. The study has determined the conditions in which water droplets join the film, rebound over it, or splash forming new smaller droplets, useful to determine the operating conditions for cooling towers so that the emission of droplet to the ambient minimizes.

Reynolds number is proved to be relevant in this phenomenon as long as values lower than 360 lead to the rebounding of the water droplet over the water film, while higher values suppose the joining of the droplet to the water film.

Future studies will include further computational simulations with the developed model to analyse the influence of the more relevant variables.

\section{ACKNOWLEDGEMENTS}

The authors acknowledge the financial support received from the Spanish Government, through Projects ENE2013-48696-C2-1-R and C2-2-R, by the FEDER (Fondo Europeo de Desarrollo Regional).

\section{REFERENCES}

[1] Lucas, M., Ruiz, J., Martinez, M.J., Kaiser, A.S., Viedma, A. \& Zamora, B., Experimental study on the performance of a mechanical cooling tower fitted with different types of water distribution systems and drift eliminators. Appl. Therm. Eng. 50, pp. 282-292, 2013. doi: http://dx.doi.org/10.1016/j.applthermaleng.2012.06.030

[2] Zamora, B. \& Kaiser, A.S., Simulación numérica del flujo turbulento de aire con gotas dispersas de agua a través de separadores de torres de refrigeración. Rev. Int. Mét. Num. Cálculo Diseño Ingen. 28, pp. 148-160, 2012.

[3] Sikalo, S., Tropea, C. \& Ganic, E.N., Impact of droplets onto inclined surfaces. J. Colloid Interface Sci. 286, pp. 661-669, 2005. doi: http://dx.doi.org/10.1016/j.jcis.2005.01.050

[4] Nikolopoulos, N., Theodorakakos, A. \& Bergeles, G., Normal impingement of a droplet onto a wall film: a numerical investigation. Int. J. Heat Fluid Flow 26, pp. 119-132, 2005. doi: http://dx.doi.org/10.1016/j.ijheatfluidflow.2004.06.002

[5] Lunkad, S.F., Buwa, V.V. \& Nigam, K.D.P., Numerical simulations of drop impact and spreading on horizontal and inclined surfaces. Chem. Eng. Sci. 62, pp. 7214-7224, 2007. doi: http://dx.doi.org/10.1016/j.ces.2007.07.036

[6] Arienti, M., Wang, L., Corn, M., Li, X., Soteriu, M.C., Shedd, T.A. \& Herrmann, M., Modelling wall film formation and breakup using an integrated interface-tracking/ discrete-phase approach. ASME Turbo Expo 2010: Power for Land, Sea, and Air, Glasgow, UK, 2010.

[7] Guide to the Expression of Uncertainty in Measurement, International Standard Organization, 1995.

[8] Lan, H., Friedrich, M. \& Armaly, B.F., Simulation and measurement of 3D shear-driven thin liquid film in a duct. Int. J. Heat Fluid Flow 29, pp. 449-459, 2008. doi: http:// dx.doi.org/10.1016/j.ijheatfluidflow.2007.12.003

[9] ANSYS, Inc., Ansys Fluent 14 Theory Guide, ANSYS, Inc., 2012. 